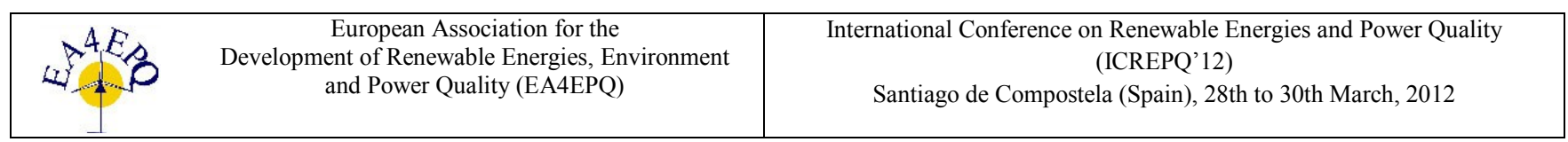

\title{
Multi-Objective Optimization of Microgrid Frequency and Energy Storage Capacity
}

\author{
M. Kohansal, G. B. Gharehpetian, M. Rahmatian and M. J. Sanjari \\ Electrical Engineering Department, Amirkabir University of Technology, Tehran. Iran \\ Phone/Fax number: +0098-21-64543504,

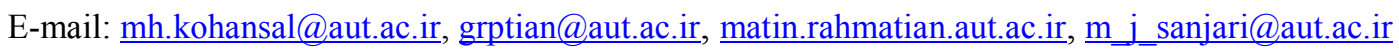

\begin{abstract}
Microgrids are systems to integrate renewable and conventional distributed energy resources under one control system. These elements are responsible for microgrid stability during and after occurrence of disturbances. The frequency stability is one of the most important issues investigated recently, specifically during islanding process. In this paper, a multi-objective function is presented and optimized by Imperialistic Competitive Algorithm to improve the frequency behaviour of the microgrid considering the energy storage capacity.
\end{abstract}

\section{Key words}

Microgrid, Frequency stability, Storage system, VSI, CSI

\section{Introduction}

Distributed generation (DG) technologies such as small wind turbines (WT), fuel cells, photovoltaic (PV) and micro turbines (MT) with storage devices like fly wheels, super capacitors and batteries on LV distribution system form microgrid (MG) [1]-[5]. A typical MG is illustrated in Fig. 1.

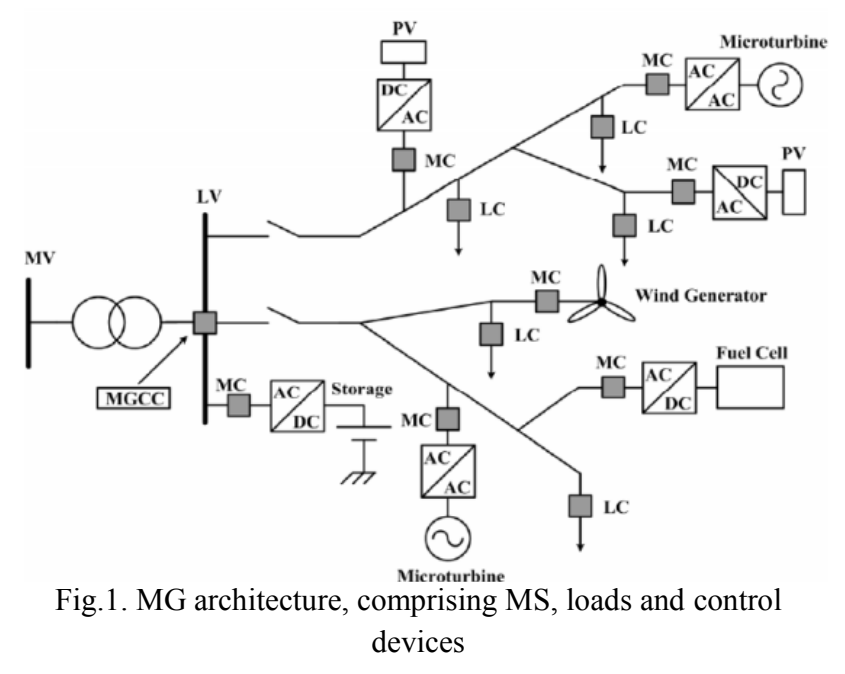

MGs are divided to noncontrollable, partially controllable and controllable sorts considering primary energy sort and dimension and the type of power interface. Small co- generation units and renewable sources that can reduce the power output only are some types of controllable and partially controllable MGs. The controllable MGs can operate in two modes:

-Normal Interconnected Mode: In this mode, the MG is connected to a medium voltage external grid and power is transferred from the MG to it or vice versa.

- Emergency Mode: In this mode, the MG is capable to operate independent from the external upstream MV network. The MG may be disconnected for many reasons such as maintenance actions or faults in the MV network.

The control strategy of MG is mainly based on hierarchical type control implemented through the $\mathrm{MG}$ Central Controller (MGCC) [3]-[4]. But this strategy leads to some frequency difficulties in islanding mode because of inexistence of enough rotating masses directly connected to the grid (inertia less system) and slow response of MS to control signals. Furthermore, local generation and local load during islanding process must be balanced by local energy resources and through an efficient application of load-shedding mechanisms and storage devices [4]. Otherwise, the MG will collapse when running to islanded operation due to imbalance of demand and supply. In some situations, high amounts of power may be needed for injection or absorption during islanding process to maintain the system stability. This amount of power depends on $\mathrm{MG}$ operating conditions such as microsource (MS) availability for active power/frequency regulation, local generation profile, local load, etc. Furthermore, most of MSs are connected to the MG via power electronic interface because of inappropriate output. Thus, the inverter control strategies are very important for performance of MSs during islanding process.

In this paper, a general model of an islanded $\mathrm{MG}$ is presented. The presented model includes inverters, microsources and energy storage systems. Also, a multiobjective function is presented with the aim of frequency behavior improvement considering energy storage capacity. 


\section{MG Architecture}

In this section modeling of different elements that are commonly used in a MG are presented.

\section{A. Microsource Modelling}

MSs are modeled diversely in the literature [6]. A simple model in exponential form is applied for all the microsources behind the inverters in this paper. This simple model can be stated as below:

$$
P(t)=(1+A * \exp (-t / \tau)) * u(t)
$$

where $P(t)$ is the output active power of a microsource, $u(t)$ is the power set-point which is derived from the inverter controller and $A$ and $\tau$ are the parameters depending on the microsource model. According to this model, the MS output changes exponentially when MS input is a step function.

\section{B. Inverter Modelling:}

Two main kinds of control strategies used for inverter operation are as below [7]:

- Current source inverter (CSI) control: The inverter is used to supply a given active and reactive power set-point. This control strategy operates to slowly that it cannot prevent quick frequency drops. However, it can compensate the frequency offsets after long time intervals through a PI controller.

- Voltage source inverter (VSI) control: Some pre-defined values of voltage and frequency are determined for the inverter. Depending on these values, the inverter feeds the load. This control strategy is the same as generators behavior in large power systems. In contrast to the previous strategy, this one can prevent the quick frequency drops successfully. Therefore, the microsources applying this strategy, i.e. behind the VSI, should be able to response to changes quickly e.g. quick storage systems.

The VSI acts as a voltage source, with the magnitude and frequency of the output voltage controlled through droops (Fig.2), as described in the following equations:

$$
\begin{gathered}
w=w_{0}-K_{P} * P \\
V=V_{0}-K_{Q} * Q
\end{gathered}
$$

Where $K_{P}$ and $K_{Q}$ are the droop slopes and $w_{0}$ and $V_{0}$ are the idle values for frequency and voltage at no loads and $P$ and $Q$ are output active and reactive power. This controller simulates the synchronous generator controller in inverters; however, inverters have no inertia. Moreover, by this strategy, loads can be shared fairly between inverters based on the nominal power of their MSs.

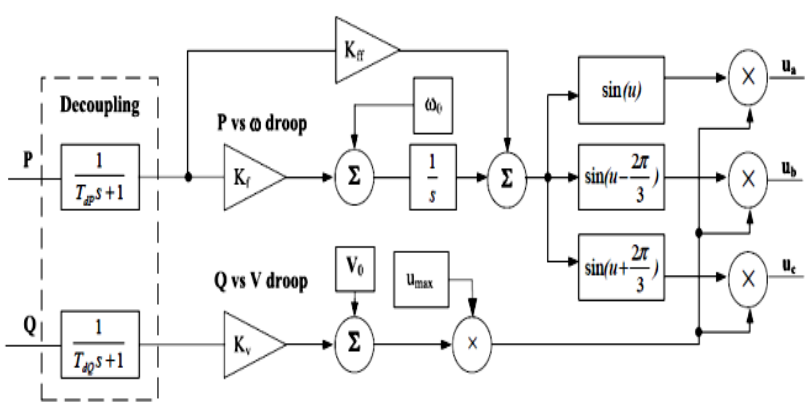

Fig. 2. VSI model

\section{Imperialism Competitive Algorithm}

Imperialist Competitive Algorithm (ICA) is a new evolutionary algorithm in the Evolutionary Computation field based on the human's socio-political evolution [8][10]. The algorithm starts with an initial random population called countries. Some of the best countries in the population selected to be the imperialists and the rest form the colonies of these imperialists. In an $N$ dimensional optimization problem, a country is a $1 \times N$ array. This array defined as below:

$$
\text { country }=\left[p 1, p 2, p 3, \ldots, p_{N}\right]
$$

The cost of a country is found by evaluating the cost function $(f)$ at the variables $\left[p 1, p 2, p 3, \ldots, p_{N}\right]$. Then

$$
c_{i}=f\left(\text { country }_{i}\right)=f\left(p 1, p 2, p 3, \ldots, p_{N}\right)
$$

The algorithm starts with $N$ initial countries and the $N_{i m p}$ best of them (countries with minimum cost) chosen as the imperialists. The remaining countries are colonies that each belong to an empire. The initial colonies belong to imperialists in convenience with their powers. To distribute the colonies among imperialists proportionally, the normalized cost of an imperialist is defined as follow:

$$
C_{n}=\max \left(c_{i}\right)-c_{n}
$$

Where, $c_{n}$ is the cost of nth imperialist and $C_{n}$ is its normalized cost. Each imperialist that has more cost value, will have less normalized cost value. Having the normalized cost, the power of each imperialist is calculated as below and based on that the colonies distributed among the imperialist countries:

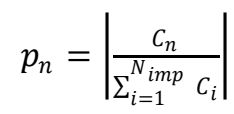

On the other hand, the normalized power of an imperialist is assessed by its colonies. Then, the initial number of colonies of an empire will be:

$$
N C_{n}=\operatorname{rand}\left(p_{n} \cdot\left(N_{c o l}\right)\right)
$$

Where, $N C_{n}$ is initial number of colonies of $n$th empire and $N_{c o l}$ is the number of all colonies. To distribute the colonies among imperialist, $N C_{n}$ of the colonies is selected randomly and assigned to their imperialist. 
After initializing, the imperialist countries start absorbing the colonies towards themselves using the absorption policy. The absorption policy (shown in Fig.3) makes the main core of this algorithm and causes the countries move towards to their minimum optima. The colony moves towards the imperialist by $x$ unit. The direction of movement is the vector from colony to imperialist, as shown in Fig.3. In this figure, the distance between the imperialist and colony shown by $d$ and $x$ is a random variable with uniform distribution. $x$ can be calculated as below:

$$
x=U(0, \beta \times d)
$$

In ICA algorithm, to search different points around the imperialist, a random amount of deviation is added to the direction of colony movement towards the imperialist. In Fig.3, this deflection angle is shown as $\theta$, which is chosen randomly and with a uniform distribution. While moving toward the imperialist countries, a colony may reach to a better position, so the colony position changes according to position of the imperialist.

$$
\theta=U(-\lambda,+\lambda)
$$

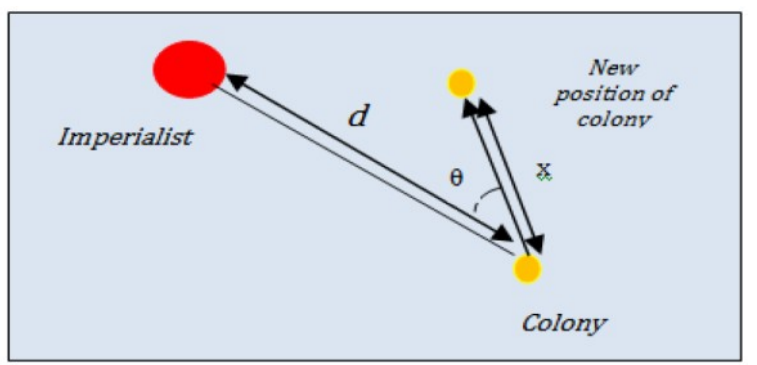

Fig. 3. Moving colonies toward their imperialist.

When a colony move toward the imperialist, the objective function of new colony sometimes become lower than imperialist. Therefore in this stage, the new colony take a role as imperialist and algorithm will continue by new imperialist. Therefore, the rest of colonies in the empire start moving toward new imperialist.

In this stage the competition between empires begins. In this competition, the weakest empires lose their colonies and other empires take them. The imperialists absorb colonies towards themselves with respect to their power that described in (11). The total power of each imperialist is determined by the power of its both parts, the empire power plus percents of its average colonies power.

$$
\begin{gathered}
T C_{n}=\operatorname{cost}\left(\text { imperialist }_{n}\right)+ \\
\xi . \operatorname{mean}\{\operatorname{cost}(\text { colonies of nth impire })\}
\end{gathered}
$$

where $T C_{n}$ is the total cost of the nth empire and $\xi$ is a positive number which is considered to be less than one. Then, the empires power need to normalize as below:

$$
N T C_{n}=\max \left(T C_{i}\right)-T C_{n}
$$

where $N T C_{n}$ is the normalized power of $n$th empire. Having the normalized power, the possession probability of each empire is mentioned as below:

$$
p_{p_{n}}=\left|\frac{N T C_{n}}{\sum_{i=1}^{N_{i m p}} N T C_{i}}\right|
$$

In above equation, each empire that has higher $p_{p_{n}}$, its probability of taking the colonies from weak empire is higher. After determining power of each empire, the power matrix of all empires formed as below:

$$
P=\left[p_{p_{1}}, p_{p_{2}}, p_{p_{3}}, \ldots, p_{p_{n}}\right]
$$

After forming the power matrix, we create a matrix as size as $P$ which its elements are random numbers between 0 and 1:

$$
R=\left[r_{1}, r_{2}, r_{3}, \ldots, r_{n}\right]
$$

Then matrix $D$ is formed by subtracting $R$ from $P$ :

$$
D=P-R=\left[d_{1}, d_{2}, \ldots, d_{n}\right]
$$

Referring to vector $D$, the colonies of weakest empire are belonged to the empires. The number of colonies that are taken from weak empire in each iteration is determined by user. We can give all colonies of weakest empire to the empire whose relevant index in $D$ is maximum value or distribute colonies to some empires based on matrix $D$ (Fig.4).

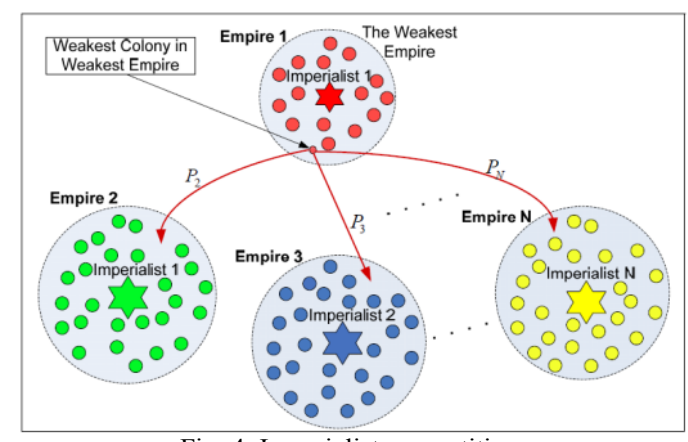

Fig. 4. Imperialist competition

In the imperialistic competition, some empires lose all of their colonies. When an empire reaches this condition, it collapses. After a while, in imperialistic competition, the most powerful empire remains and it takes all colonies of other empires. Actually other empires collapse in this competition by losing their colonies. If algorithm is continued, all of colonies are became as the same as imperialist of the remaining empire. Actually there are no differences between colonies and imperialist in the empire.

\section{Simulation Results}

A MG network is simulated in DIgSilent software based on the procedure discussed in section two (Fig.5). The MG is connected to the external grid through bus 1 . At this bus, a flywheel (as an energy storage system) is located. A VSI controller is applied for flywheel's inverter. Other sources are connected to the MG based on the CSI mode. In simulation, the external grid disconnected from $\mathrm{MG}$ in $t=0.2 \mathrm{~s}$. Loads and generations 
are in the worst operation condition as listed in table I. Considering these values, the frequency has the most deviation.

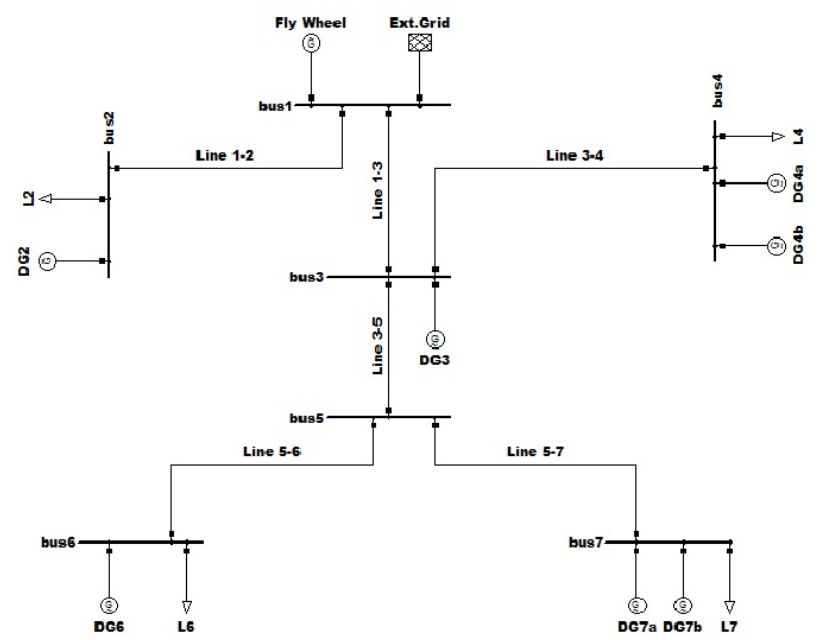

Fig. 5. The network schematic

Table I. Power of DGs and loads

\begin{tabular}{|c|c|}
\hline Sources and loads & $P(\mathrm{~kW})$ \\
\hline DG2 & 30 \\
\hline DG4a & 15 \\
\hline DG4b & 10 \\
\hline DG6 & 5 \\
\hline DG7a & 10 \\
\hline DG7b & 5 \\
\hline Load2(L2) & 60 \\
\hline Load4(L4) & 30 \\
\hline Load6(L6) & 25 \\
\hline Load7(L7) & 20 \\
\hline Ext.Grid & 60 \\
\hline
\end{tabular}

In Fig.6, the frequency deviation after islanding process is shown. The frequency faces two major drops at $t=0.2 \mathrm{sec}$, i.e. disconnection instant and $t=17 \mathrm{sec}$. The first drop is a result of imbalance between generated active power and demand in the disconnection moment while the second drop is related to the energy depletion of storage device connected to the VSI (Flywheel).

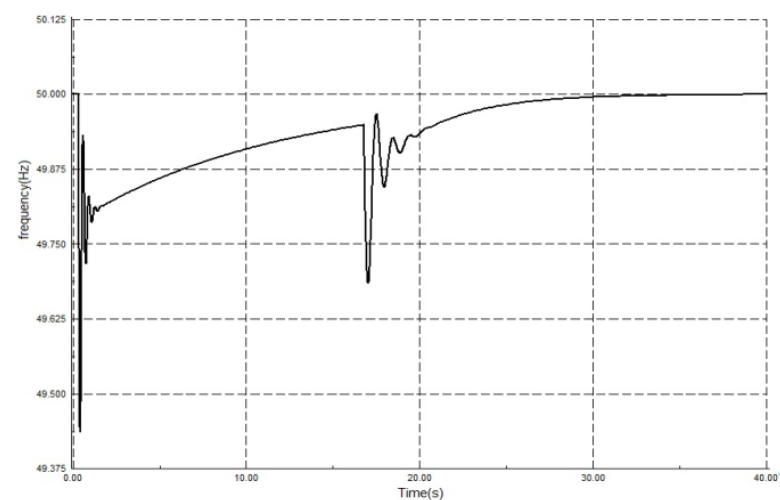

Fig. 6. Frequency deviation during islanding process
The remaining energy and output power of the flywheel are shown in Fig.7 and Fig.8, respectively. At $t=17 \mathrm{sec}$, when the energy of the Flywheel is consumed completely, its output power reaches zero. Consequently, it is obvious that the frequency drop is directly related to the storage system energy. More energy storage results in less frequency drop.

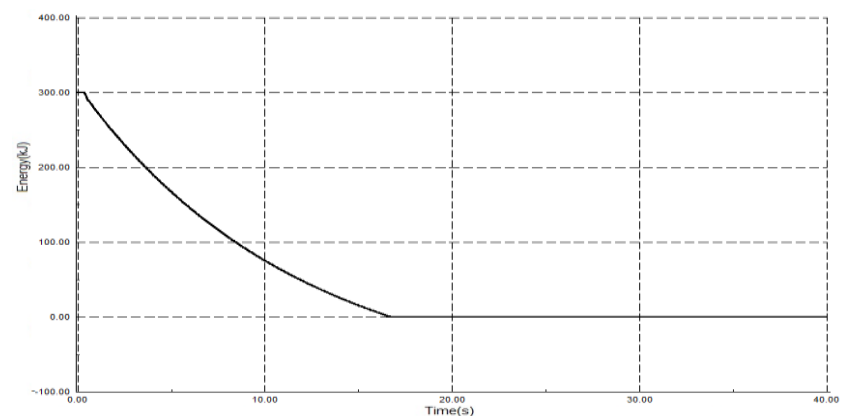

Fig. 7. Remaining flywheel energy

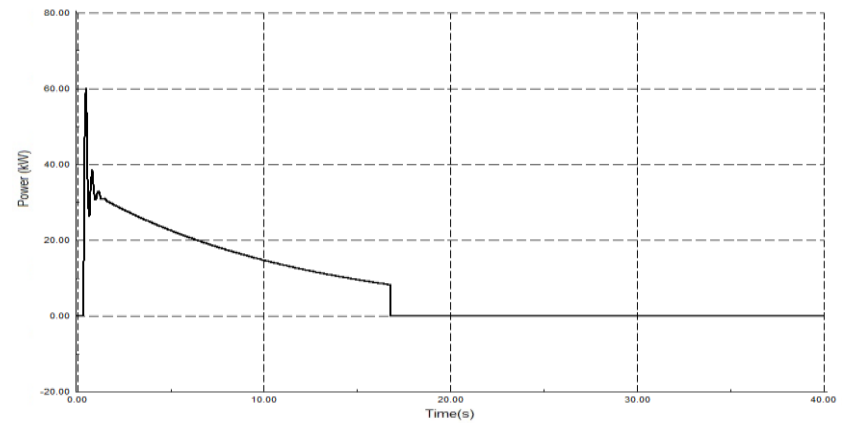

Fig. 8. Active power output of flywheel

During the optimization process, two expressions have been considered: the frequency drop integration and the energy capacity of storage system $\left(\mathrm{EC}_{\mathrm{ss}}\right)$ which is a criterion for its cost. More cost of the storage system expresses more storage capacity and consequently more capability for compensation of frequency drop. Therefore, the two terms of the objective function behave contrastingly versus each other. Moreover, the terms' weights $\left(w_{i}\right)$ in the objective function are considered based on the importance of them.

$$
\begin{gathered}
\text { objective function }= \\
w_{1} * \int(f-50)^{2} d t+w_{2} * E C_{s S}
\end{gathered}
$$

The optimization problem is solved using ICA. The optimal energy storage capacity for $w_{1}=w_{2}=0.5$ is $250 \mathrm{~kJ}$. In table II, the final result is compared with the other two situations.

Table II. Optimum Capacity

\begin{tabular}{|c|c|}
\hline Energy of Flywheel (J) & $\begin{array}{c}\text { Value of objective } \\
\text { function }\end{array}$ \\
\hline 100000 & 0.84 \\
\hline 250000 & 0.69 \\
\hline 400000 & 0.81 \\
\hline
\end{tabular}




\section{Conclusion}

In this paper, the relation between the energy capacity of the storage system and the frequency behavior during and after the occurrence of disturbances in a microgrid is described. This study results in a trade-off between them. In other words, more energy storage results in less frequency drop. But, from economical point of view, the increasing capacity of the storage system must be limited. Therefore, a multi-objective function is presented with the aim of frequency behavior improvement considering energy storage capacity. This function is optimized using ICA and the results present the best performance of the MG with a satisfactory energy storage capacity.

\section{References}

[1] R. Lasseter and P. Piagi, "Providing premium power through distributed resources", Proc. 33rd Hawaii International Conference on System Science, January 2000.

[2] R. Lasseter, "Microgrids", IEEE PES Winter Meeting, $27-$ 31 January 2002, vol. 1, pp. 305-308.

[3] F. Katiraei, M. Iravani, and P. Lehn, "Micro-grid autonomous operation during and subsequent to islanding process," IEEE Trans. Power Del., vol. 20, no. 1, pp. 248257, Jan. 2005
[4] A. Peças Lopes, L. Moreira and G. Madureira, "Defining control strategies for MicroGrids islanded operation", IEEE Transactions on Power Systems, May 2006, vol. 21, no. 2, pp. 916-924.

[5] P. Piagi and R. Lasseter, "Autonomous control of Microgrids" IEEE PES General Meeting, 18-22 June 2006.

[6] P. Wirtanen, "Simulation of the Management of a Micro Grid with Wind, Solar and Gas Generators", Master's Thesis for the degree of Master of Science in Engineering, Aalto University School of Science and Technology, October 2009.

[7] C. Lee, C. Chuang, C. Chu and P. Cheng, "Control Strategies for Distributed Energy Resources Interface Converters in the Low Voltage Microgrid," Proc. IEEE ECCE, 2009

[8] E. Atashpaz Gargari and C. Lucas, "Imperialist competitive algorithm: An algorithm for optimization inspired by imperialistic competition", IEEE Congress on Evolutionary Computation, 2007.

[9] A. Khabbazi, E. Atashpaz and C. Lucas, "Imperialist Competitive Algorithm for Minimum Bit Error Rate Beam forming", To be appeared in International Journal of BioInspired Computation (IJBIC).

[10] A. M. Jasour, E. Atashpaz and C. Lucas, "Vehicle Fuzzy Controller Design Using Imperialist Competitive Algorithm", Second First Iranian Joint Congress on Fuzzy and Intelligent Systems, Tehran, Iran, 2008. 